\title{
Sulfonation and Characterization of Styrene-Indene Copolymers for the Development of Proton Conducting Polymer Membranes
}

\author{
Cristiane M. Becker, Amanda B. Biagini, Maria M. C. Forte, Sandro C. Amico \\ Programa de Pós-graduação em Engenharia de Minas, Metalúrgica e de Materiais, UFRGS \\ José V. C. Vargas \\ Departamento de Engenharia Mecânica, UFPR \\ Denise S. Azambuja \\ Programa de Pós-graduação em Química, UFRGS
}

\begin{abstract}
The aim of this work is to obtain polymer precursors based on styrene copolymers with distinct degrees of sulfonation, as an alternative material for fuel cell membranes. Acetyl sulfate was used to carry out the sulfonation and the performance of the polyelectrolyte was evaluated based on the content of acid polar groups incorporated into the macromolecular chain. Polymeric films were produced by blending the sulfonated styrene-indene copolymer with poly(vinylidene fluoride). The degree of sulfonation of the polymer was strongly affected by the sulfonation reaction parameters, with a direct impact on the ionic exchange capacity and the ionic conductivity of the sulfonated polymers and the membranes obtained from them. The films produced with the blends showed more suitable mechanical properties, although the conductivity of the membranes was still lower than that of commercially available membranes used in fuel cells.
\end{abstract}

Keywords: Styrene-indene, fuel cells, sulfonation, blends.

\section{Introduction}

Proton conducting polymer electrolyte membranes, also known as proton exchange membranes (PEM), have been receiving great attention due to their application in a variety of electrochemistry-based technologies, such as batteries, supercapacitors, electrochromic windows, displays or sensors, and fuel cells ${ }^{[1-3]}$. The development of fuel cells (FC), in particular, has been the subject of many studies during the last decades partly due to environmental concerns related to traditional energy sources ${ }^{[4,5]}$.

Proton exchange membrane fuel cells (PEMFC) are well established since the early 1960 s, being successfully used as electrical power sources for spacecrafts. More recently, effort is being made to expand their application to mass products, such as electrical vehicles and portable devices ${ }^{[6]}$, increasing interest in materials used as electrolytes for FC, i.e. permselective ion-exchange membranes, such as Nafion ${ }^{\circledR}$. Polymeric materials may behave as electrolytes depending on their ionic conductivity characteristics, which may be manipulated via functionalization, i.e., the attachment of ionizable groups (e.g. sulfonic) to the organic polymer backbone.

Sulfonation is a powerful and versatile technique which can be used to render some polymers proton conductive and hydrophilic ${ }^{[7,8]}$. The degree of sulfonation can be controlled and adjusted to maximize, for instance, polymer proton conductivity ${ }^{[2,6]}$. In Nafion ${ }^{\circledR}$ membranes, sulfonic ionizable groups $\left(-\mathrm{SO}_{3} \mathrm{H}\right)$ are covalently attached to the side chains of the main fluorinated chains. These highly acidic groups, when sufficiently hydrated, dissociate producing $\mathrm{H}^{+}$, a mobile counter-ion ${ }^{[9]}$.

The high cost of Nafion ${ }^{\circledR}$ is driving the development of new materials, and hydrocarbon resins, such as those comprised of styrene-indene copolymer, may be an alternative for the production of less costly membranes since their molecular structure allow the insertion of polar pendant groups in the chain, increasing their conductivity and hydrophilicity ${ }^{[4]}$. In addition, a number of recent publications report on the use of sulfonated polystyrene for the production of ion exchange membranes ${ }^{[10]}$ and, in this sense, styrene-indene copolymers could be a viable alternative for that. In this context, this work reports on the synthesis and characterization of sulfonated styrene-indene copolymers and the preparation and characterization of films produced with their blends with poly(vinylidene fluoride) (PVDF).

\section{Experimental}

A commercial grade styrene-indene copolymer hydrocarbon resin (Unilene BS 140) supplied by Braskem S.A. was sulfonated with acetyl sulfate, following the procedure described by Makoski and Lundberg ${ }^{[10]}$. The acetyl sulfate solution was prepared by mixing dichloroethane and acetic anhydride under inert atmosphere $\left(\mathrm{N}_{2}\right)$. The solution was cooled to $0{ }^{\circ} \mathrm{C}$ and sulfuric acid was then carefully added. This reaction mixture was stirred at room temperature until a homogeneous solution was achieved. An excess of acetic anhydride was used to quench any trace of residual water. The acetyl sulfate was prepared just prior to each sulfonation reaction.

Distinct amounts of the copolymer were dissolved in dichloroethane and this solution was heated to $60{ }^{\circ} \mathrm{C}$ until thorough solubilization of the samples and purged with $\mathrm{N}_{2}$ for 30 minutes at $1 \mathrm{~atm}$. After that, the acetyl sulfate solution was added using a separator funnel. The reaction mixture was kept at $60{ }^{\circ} \mathrm{C}$ under stirring for a variable period of time (see Table 1). The reaction was interrupted by adding an excess of methanol and, after 30 minutes, the reactional mixture was cooled to room temperature. Finally, the sulfonated material was isolated in hexane, re-precipitated in distilled water and dried in an oven at $70{ }^{\circ} \mathrm{C}$.

PVDF commercial grade (Solef 1008/Solvay) was previously swollen and dissolved in N,N-dimethylfomamide (DMF) using $10 \mathrm{~g}$ of PVDF in $3 \mathrm{~mL}$ of (DMF) and a particular amount of the sulfonated resin was added to the solution under stirring. All PVDF/ sulfonated blends (20 to 80 wt. (\%) of PVDF) were obtained by casting the polymeric solution onto a glass plate and drying at $70^{\circ} \mathrm{C}$ for 2 hours or until stabilization of the weight, i.e. the volatilization of all DMF. Even though this temperature was much inferior to the

Autor para correspondência: Cristiane M. Becker, Programa de Pós-graduação em Engenharia de Minas, Metalúrgica e de Materiais, Universidade Federal do Rio Grande do Sul - UFRGS, Av. Bento Gonçalves, 9500, Bairro Agronomia, CEP 91501-970, Porto Alegre, RS, Brasil, e-mail: cristiane.becker@ufrgs.br 
Table 1. Sulfonation parameters and respective reaction yield, degree of sulfonation (DS) and ion exchange capacity (IEC) obtained.

\begin{tabular}{|c|c|c|c|c|c|}
\hline Sample & $\frac{\mathrm{CH}_{3} \mathrm{COOSO}_{3} \mathrm{H}(\mathrm{mol})}{\operatorname{resin}(\mathrm{mol})}$ & Reaction time (hours) & Yield (\%) & DS (\%) & IEC $\left(\mathrm{mEq} \cdot \mathrm{g}^{-1}\right)$ \\
\hline BS-1 & 0.4 & 3.0 & 80.2 & 12.3 & 1.02 \\
\hline BS-2 & 1.0 & 2.5 & 69.4 & 25.3 & 1.93 \\
\hline BS-3 & 1.5 & 2.5 & 70.0 & 33.2 & 2.42 \\
\hline BS-4 & 1.5 & 3.0 & 65.8 & 37.0 & 2.64 \\
\hline BS-5 & 2.0 & 2.5 & 67.0 & 45.0 & 3.07 \\
\hline BS-6 & 2.0 & 3.0 & 65.4 & 55.6 & 3.58 \\
\hline
\end{tabular}

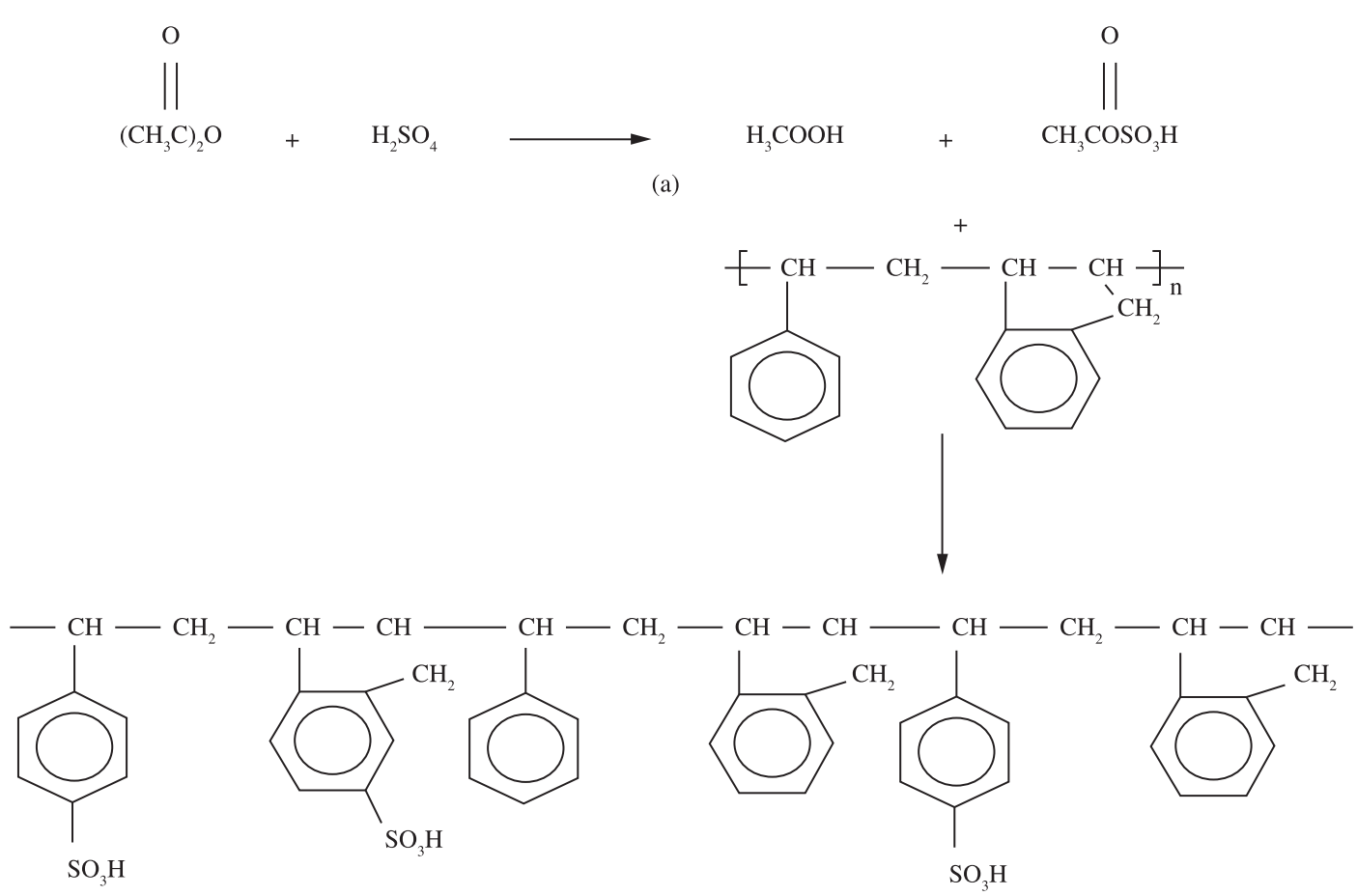

(b)

Figure 1. Sulfonation reaction scheme: (a) acetyl sulfate and (b) styrene-indene copolymer sulfonation.

boiling temperature of the DMF, thorough volatilization of the small amount of solvent is expected to have occurred.

Polymer sulfonation was qualitatively evaluated following the $-\mathrm{SO}_{3} \mathrm{H}$ characteristic absorbance band on the FT-IR (Perkin Elmer Spectrum 1000) spectrum of the sulfonated copolymer. The degree of sulfonation (DS) and the ion-exchange capacity (IEC) of the sulfonated resins were determined ${ }^{[8,11]}$ by dissolving around $0.3 \mathrm{~g}$ of the dry polymer in methyl alcohol and titrating it with a standard $(0.02 \mathrm{M}) \mathrm{NaOH}$ solution, using phenolphthalein as indicator to enable the evaluation of the concentration (mols) of $\mathrm{H}^{+}$ released into the solution. DS and IEC of the sulfonated polymers were determined using $D S=\frac{110 \times M_{\mathrm{NaOH}} \times V_{\mathrm{NaOH}} \times 10^{-3}}{W-\left(81 \times M_{\mathrm{NaOH}} \times V_{\mathrm{NaOH}}\right) \times 10^{-3}}$ and $I E C=1000 \times D S /(110+81 \times D S) \overparen{A B C}$, where: $M_{\mathrm{NaOH}}$ is the concentration of the $\mathrm{NaOH}$ solution $(\mathrm{mol} / \mathrm{L}), V_{\mathrm{NaOH}}$ is the volume of the $\mathrm{NaOH}$ solution used to neutralize the sulfonated polymer solution $(\mathrm{mL}), W$ is the sample weight $(\mathrm{g})$, and 110 and 81 are the molecular weights of the repeating unit of the styrene-indene copolymer and of the $-\mathrm{SO}_{3} \mathrm{H}$ group, respectively.

Thermal stability of the sulfonated resins and the blends was evaluated via thermogravimetric analysis (TGA) using a TA Instrument 2050 analyzer, from 25 to $1000^{\circ} \mathrm{C}$, at a heating rate of $20^{\circ} \mathrm{C} / \mathrm{min}$, under inert atmosphere. TGA was used to analyse the resin samples, before and after sulfonation, and the 50\% PVDF/50\% sulfonated resin blend.

The sulfonated resins and the PVDF/sulfonated resin blends, of distinct composition, were investigated using impedance experiments. Films obtained from the samples were sandwiched between two stainless steel (SS304) electrodes assembled into an epoxy resin holder following the procedure described in the literature ${ }^{[11]}$. Thickness of the films varied within $20-32 \mu \mathrm{m}$ and the area was about $1.5 \mathrm{~cm}^{2}$. Impedance measurements at $25{ }^{\circ} \mathrm{C}$ and at relative humidity of $70 \%$ were performed using an Autolab Pgstat 30/FRA 2 system operating in the $10 \mathrm{kHz}-10 \mathrm{MHz}$ frequency range and with $10 \mathrm{mV}$ of amplitude of the sinusoidal voltage.

To evaluate water uptake $\left(\varphi_{w}\right)$, or swelling, three samples of $\mathrm{PVDF} /$ sulfonated resins blends were dried under vacuum at room temperature until constant weight $\left(w_{\text {dry }}\right)$. They were then immersed in water at room temperature and, after 24 hours, the swollen samples were removed from the water, slightly wiped up with a dry cloth and immediately weighted $\left(w_{\text {wet }}\right)$. Swelling was evaluated using $\varphi_{w}=\left(w_{\text {wet }}-w_{d r y}\right) \times 100 / w_{d r y}{ }^{[12-14]}$. Morphology of the blends was investigated using a JSM 6060 (Jeol) scanning electron microscope (SEM) operating at $10 \mathrm{keV}$. SEM specimens were prepared by cryogenic fracturing the samples and gold-sputtering them prior to the analysis. 


\section{Results}

Sulfonation of the styrene-indene copolymer is believed to have occurred in both styrene and indene units ${ }^{[3]}$, and a possible reaction scheme is shown in Figure 1. The insertion of sulfonic groups $\left(-\mathrm{HSO}_{3}\right)$ in the polymer chain may favour proton conductivity. The degree of sulfonation (DS) achieved under different reaction conditions is shown in Table 1. DS varied in the 12.3-55.6\% range, increasing with the concentration of the sulfonating agent and also with the duration of the reaction. Water sorption varied with the extent of sulfonation, i.e. the higher the DS, the greater the swelling and the water solubility. In this study, sulfonated resins with DS higher than $45 \%$ were fully soluble in water at room temperature.

The yield of the sulfonation reaction, also shown in Table 1, varied between 65.4 and $80.2 \%$, according to the specific reaction conditions. It can be observed that yield decreased with the increase in DS. For a DS of $12 \%$, the polymer resin could be easily collected. On the other hand, for DS higher than $45 \%$, recovery of the polymer was hindered by its high solubility in water, decreasing the estimated reaction yield. The IEC varied between 0.99 and $3.55 \mathrm{mEq} . \mathrm{g}^{-1}$ (see Table 1), in a way that the higher the DS, the higher the IEC, as expected.

Figure 2 shows the FT-IR spectra of non-sulfonated and sulfonated styrene-indene copolymers (samples BS-2 and BS-6). The spectra confirmed the presence of sulfonated groups in the copolymers after sulfonation, since the 1156, 1127, 1034 and $1006 \mathrm{~cm}^{-1}$ peaks are all associated with the stretching vibrations of the sulfonic group ${ }^{[1,2,15,16]}$. The absorption bands at 1006 and $1127 \mathrm{~cm}^{-1}$ are associated with in-plane band vibrations of the aromatic ring para-substituted with the sulfonated group and with the sulfonated anion attached to the aromatic ring, respectively.

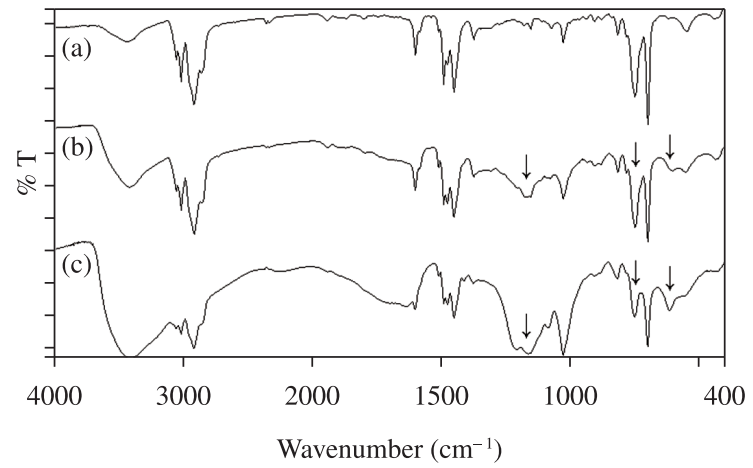

Figure 2. FT-IR spectra of the non-sulfonated (a), the BS-2 (b) and the BS-6 (c) sulfonated resins.

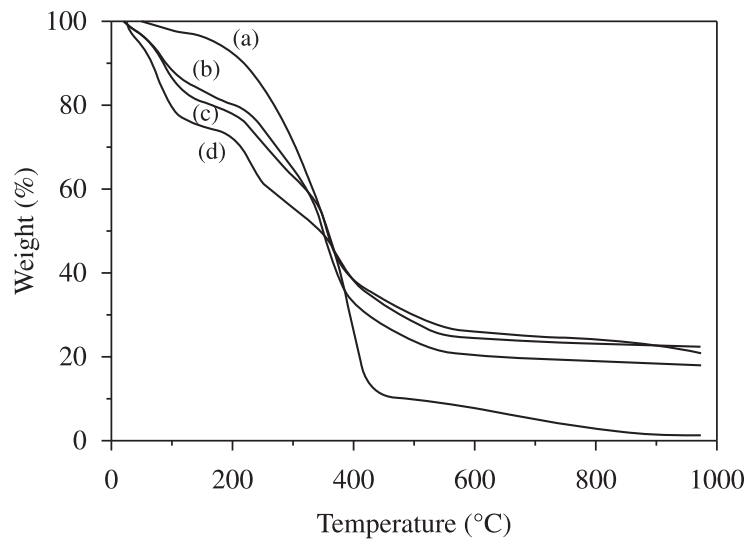

Figure 3. TGA of the non-sulfonated resin (a), the BS-2 (b), the BS-3 (c) and the BS-6 (d) sulfonated resins.
Besides, the bands at 1034 and $1156 \mathrm{~cm}^{-1}$ represent the symmetric and asymmetric stretching vibrations of the sulfonic groups, respectively. It may also be seen in Figure 2 that the intensity of these bands increased with the degree of sulfonation (samples $\mathrm{BS}-2-\mathrm{DS}=25 \%$ and BS-6 $-\mathrm{DS}=55 \%$ ).

The TGA curves obtained for the non-sulfonated and the sulfonated styrene-indene copolymers are shown in Figure 3. The sulfonated resin showed lower thermal stability in comparison with the non-sulfonated. In fact, sulfonated resins showed significant weight loss starting as low as $80{ }^{\circ} \mathrm{C}$, which is related to the loss of absorbed water (moisture) ${ }^{[17]}$. Hydrophilicity of the sulfonated

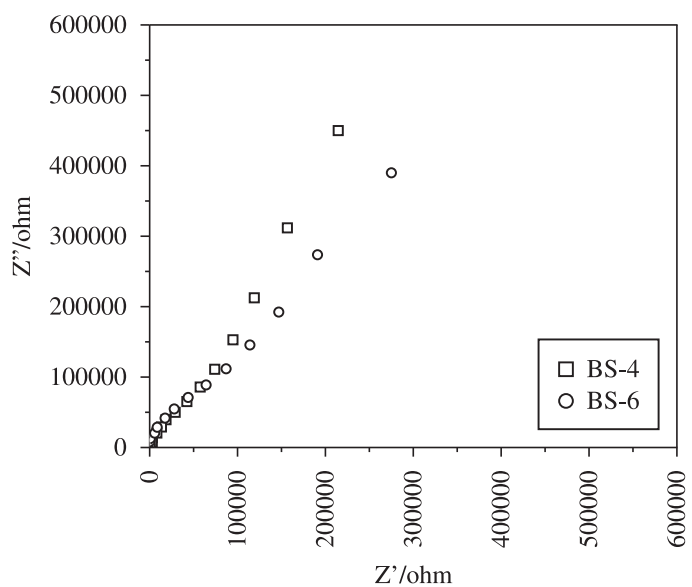

(a)

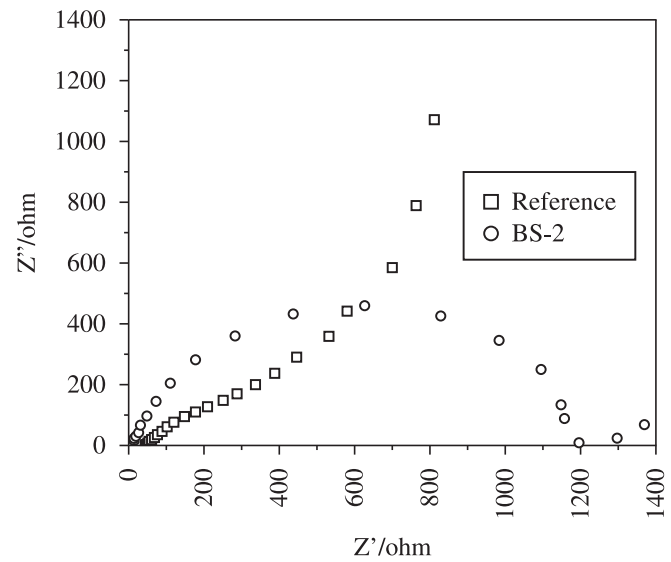

(b)

Figure 4. Impedance Nyquist plot for the sulfonated resins BS-4 (DS $=37 \%$ ) and BS-6 (DS $=57 \%)(a)$, and for BS-2 (DS $=25 \%)$ and a commercial membrane (b).

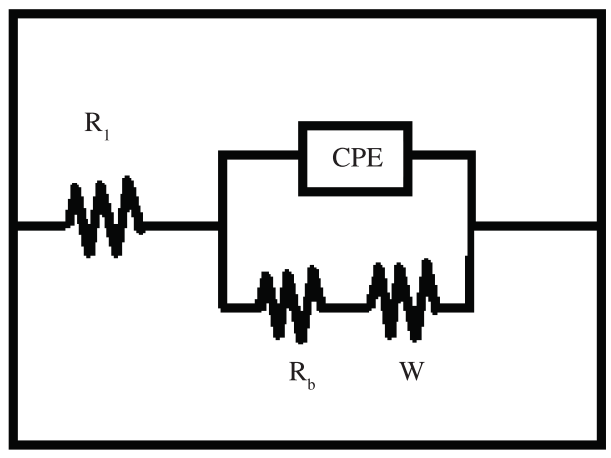

Figure 5. Equivalent circuit proposed. 


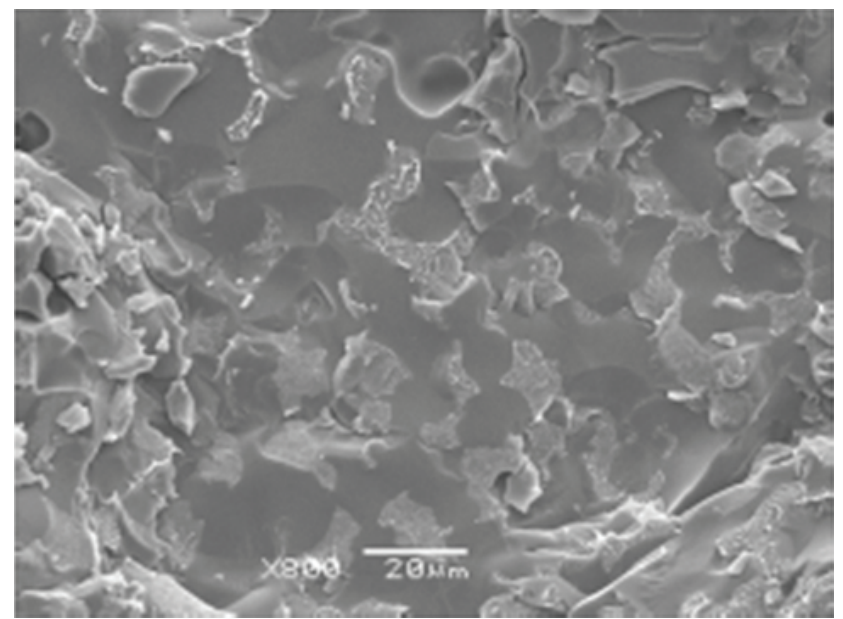

(a)

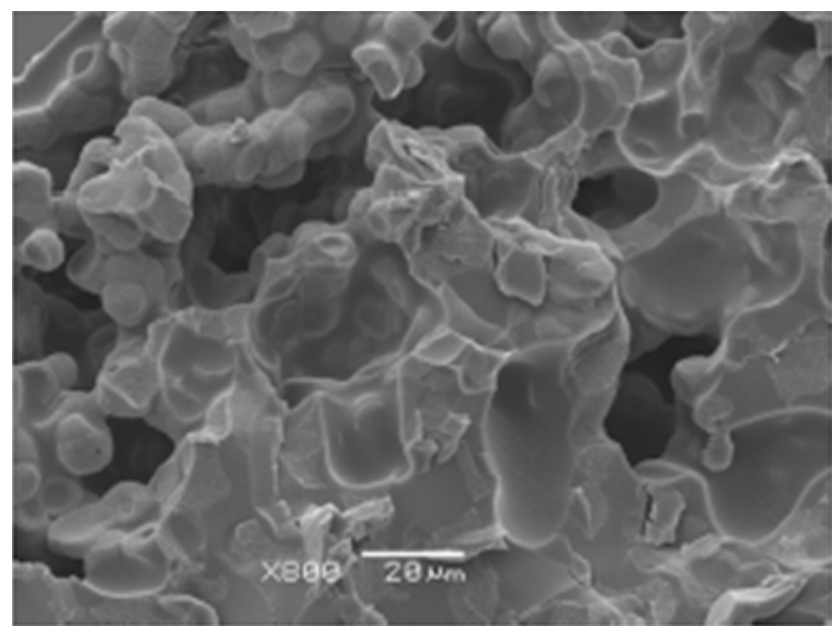

(c)

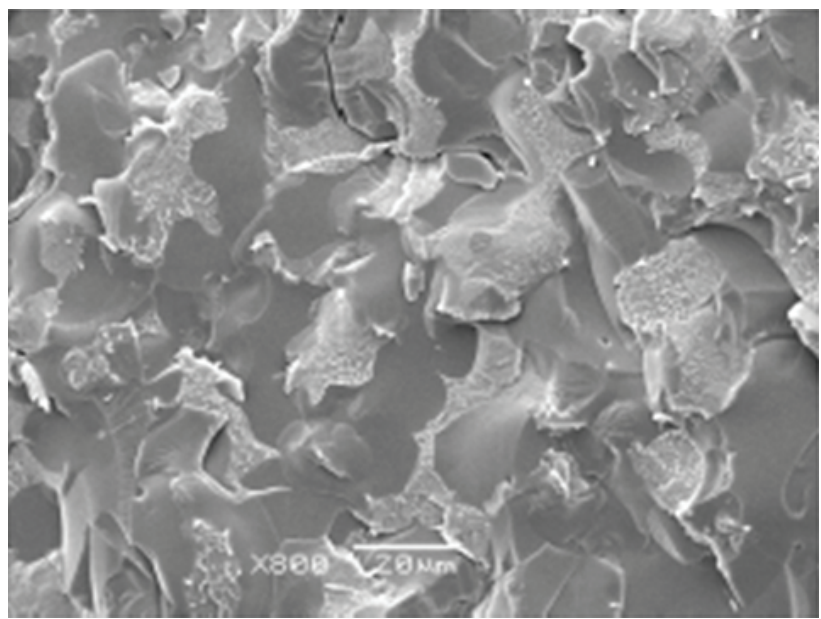

(b)

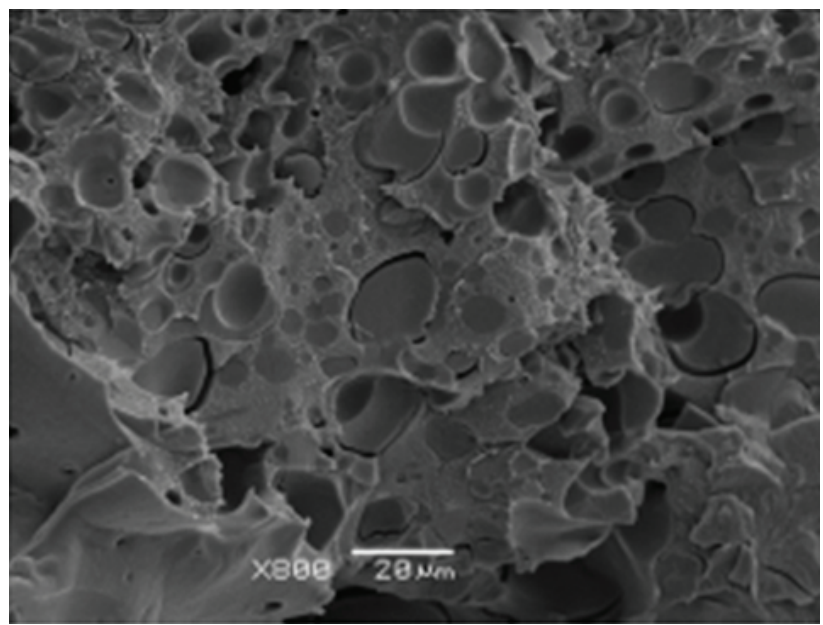

(d)

Figure 6. Micrographs of the BS/PVDF 50/50 blends: BS-1/PVDF (a), BS-2/PVDF (b), BS-3/PVDF (c) and BS-6/PVDF (d).

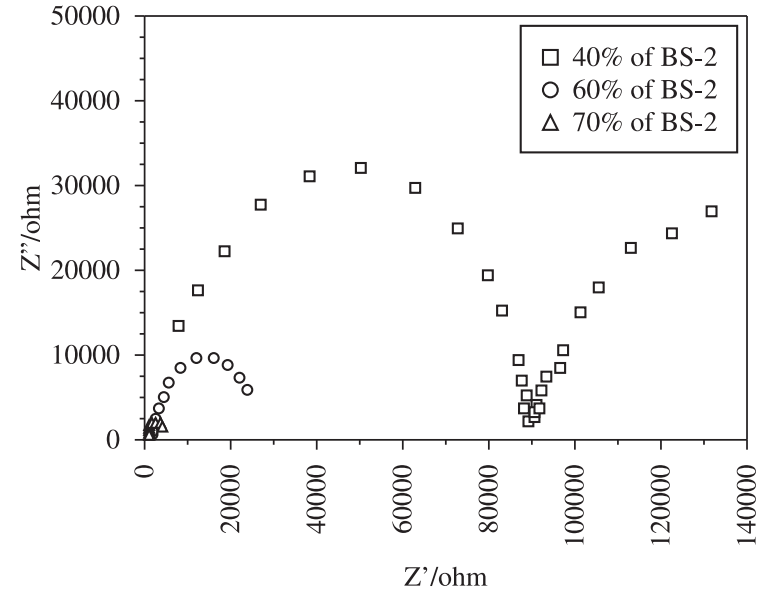

Figure 7. Impedance Nyquist plot for the BS-2/PVDF blends.

copolymers, which increased with the degree of sulfonation, may be responsible for this early weight loss, i.e. the higher the DS, the higher the weight loss. The weight loss event around $260{ }^{\circ} \mathrm{C}$, which is associated with the thermal degradation of the sulfonic groups ${ }^{[2]}$, was more significant for samples with higher content of sulfonic groups. The resin degraded around $340{ }^{\circ} \mathrm{C}$ and the sulfonated resins showed a similarly high residue content (at $1000^{\circ} \mathrm{C}$ ) in comparison with the original polymer. The residue content increased with the sulfonation degree, e.g. from $1.3 \%$ for the non-sulfonated copolymer to $18.4 \%$ for BS-2 and to $22.4 \%$ for BS-6. The decomposition of the sulfonic acid groups may promote carbonization of the polymer, being perhaps responsible for the high residue content of the sulfonated samples in comparison with the non-sulfonated copolymers.

Impedance spectroscopy results of the sulfonated resins and the blends were compared with those of a commercial polymeric membrane used as reference. The Nyquist plots of the BS-4 and BS- 6 are given in Figure 4a and those of BS-2 and the commercial membrane in Figure 4b. The BS-4 and BS-6 showed two time constants. In the high frequency range, a capacitive loop was detected and, for lower frequencies, the diffusion of charge transfer in the polymer film was dominant. Moreover, on decreasing the sulfonation degree from $55.6 \%$ to $25 \%$ (samples BS-6 and BS-2, respectively), the diameter of the capacitive loop substantially decreased, indicating a decrease in membrane resistance.

The obtained EIS spectrum for the reference sample was similar to that found in the literature ${ }^{[18]}$. Regarding the produced resins, BS-2 showed less ionic resistance than the reference. Figure 5 displays the equivalent circuit (EC) which was found to satisfactorily fit the EIS diagrams shown in Figure 4, corresponding to $R_{l}$. $\left(C P E .\left[R_{b} \cdot W\right]\right)$, where: $R_{l}$ represents the polymer/electrode interfacial resistance ${ }^{[1,20]}$, $R_{b}$ represents the bulk resistance, and $C P E$ is the impedance related to a constant phase element. The capacitance was replaced by a $C P E$ 
Table 2. Resistance and conductivity of the samples and the parameters calculated from the impedance results (Figure 4) using the equivalent circuit shown in Figure 5.

\begin{tabular}{lcccccc}
\hline Sample & $\mathbf{R}_{\mathbf{1}}(\Omega)$ & $\mathbf{R}_{\mathbf{b}}\left(\times \mathbf{1 0}^{\mathbf{3}} \Omega\right)$ & $\mathbf{C P E}\left(\mathbf{1 0}^{-\mathbf{5}} \mathbf{F}\right)$ & $\mathbf{N}$ & $\mathbf{W}(\Omega)$ & $\mathbf{d} / \mathbf{S}\left(\mathbf{c m}^{-1}\right)$ \\
\hline BS-2 & 9.6 & 1.21 & 0.28 & 0.84 & 31.6 & 0.133 \\
BS-4 & 21.7 & 114.6 & 0.36 & 0.80 & $28 \times 10^{4}$ & $0.2 \times 10^{-3}$ \\
BS-6 & 29.4 & 107.9 & 0.85 & 0.88 & $18 \times 10^{4}$ & 1.173 \\
Reference & 41.2 & 0.353 & 1.67 & 0.67 & $9.6 \times 10^{-7}$ & 341 \\
\hline
\end{tabular}

Table 3. Swelling of the BS-2/PVDF films.

\begin{tabular}{cc}
\hline BS-2/PVDF (w/w) & Swelling (\%) \\
\hline $20 / 80$ & $4.1 \pm 0.9$ \\
$30 / 70$ & $8.2 \pm 2.2$ \\
$40 / 60$ & $28.9 \pm 3.2$ \\
$50 / 50$ & $42.1 \pm 4.5$ \\
$60 / 40$ & $72.3 \pm 4.3$ \\
$70 / 30$ & $78.8 \pm 6.2$ \\
$80 / 20$ & $232 \pm 10.3$ \\
\hline
\end{tabular}

impedance, which takes into account the effects related to roughness and non-homogeneity of the electrode surface. The $C P E$ impedance is given by $Z_{C P E}=\left[Q(j \omega)^{n}\right]^{-1}{ }^{[19]}$, where $C P E$ represents an ideal capacitor for $n=1.0$ and a resistor for $n=0.0$. The Warburg impedance, $W$, which is in serial connection with $R_{b}$, takes into account the diffusion process. The high frequency semicircle is associated with a combination of Rb.CPE and $W$, corresponding to the bulk properties and the effects related to dielectric relaxations.

Thus, the ionic conductivity of the film can be calculated by $\delta=\frac{1}{R_{b}} \times \frac{d}{S}$, where: $\delta$ is the ionic conductivity, $d$ the film thickness and $S$ the electrode area contacting the film. The ionic conductivity of the sulfonated polymers was determined from the fitted $R_{b}$ values.

The simulated values corresponding to the data given in Figure 4 are shown in Table 2. Analysis of the fitted data indicates that the BS-2 sample (DS $=25 \%$ ) presented the lowest $R_{b}$ and Warburg impedance values among the tested samples, favoring ionic transport (conductivity) in the membranes, i.e. the resistance to charge transport within the polymer film decreased. For higher DS values (i.e. samples BS-4 and BS-6), resistance increased, which may be explained by the stronger interaction between the sulfonic groups in the highly sulfonated samples, since these groups show greater resistance to dissociation ${ }^{[21]}$.

Moreover, a $C P E$ element with $n$ close to 0.8 indicates a non-homogeneous electrode surface. This suggests that morphology and roughness of the membranes varied with the composition, affecting the resistance of the polymer films. The calculated ionic conductivity of the BS-2 film (with DS $=25 \%$ ) was higher than that of the reference $\left(4.2 \times 10^{-3}\right.$ and $3.5 \times 10^{-4} \Omega^{-1} \mathrm{~cm}^{-1}$, respectively).

Swelling due to water absorption is a key factor regarding mechanical integrity of the membranes and excessively high water content leads to dimensional changes and premature mechanical failure. In order to decrease solubility of highly sulfonated membranes, polymer blends were prepared by mixing the resin with PVDF. The BS-2 sample was chosen to produce the blends because it showed the lowest solubility in water and the highest conductivity. Table 3 shows the measured swelling of the various BS-2/PVDF blends and nearly no swelling was observed for a low content of sulfonated resin, although it considerably increased with the BS-2 content.
In membranes for fuel cell applications, a continuous network of a proton-conducting phase within the material is essential. For the studied system, the sulfonated resin must be present as a continuous network within the PVDF matrix. Morphology characterization of the blends with low DS (i.e. BS-1 and BS-2) evidenced the presence of a homogeneous phase with nonporous aspect (Figures 6a, b). However, many pores may already be observed for the BS-3 blends (Figure 6c) which may be attributed to the incompatibility between the two compounds that could promote retention of the DMF within the film, later producing pores during solvent evaporation. When DS increased further (as for BS-6), two phases were clearly visible (Figure 6d). In the latter, the hydrophilic ionic phase showed some degree of segregation, indicating higher incompatibility among the blend components. Based on these images, it can be inferred that connectivity and aggregation were dependent on DS.

Figure 7 shows the Nyquist plots for three of the BS-2 blends. Resistance of the films increased from $3.45 \mathrm{k} \Omega$ (for the $70 \% \mathrm{BS}-2$ blend) to $112 \mathrm{k} \Omega$ (for the $40 \%$ BS-2 blend), corresponding to a decrease in conductivity from $3.45 \times 10^{-5}$ to $1.19 \times 10^{-6} \Omega^{-1} \mathrm{~cm}^{-1}$.

\section{Conclusions}

Hydrocarbon resins of styrene-indene copolymers were readily functionalized, producing a sulfonated resin containing up to $55 \%$ of sulfonic groups. Furthermore, the degree of sulfonation was easily tailored within a wide range and showed a direct impact on the ion-exchange capacity and the ionic conductivity of the polymers.

Thermogravimetric analyses showed that the increase in the degree of sulfonation and IEC yielded greater weight loss at lower temperatures, a consequence of the liberation of adsorbed water and the decomposition of sulfonic groups. Besides, conductivity of the sulfonated resin called BS-2 was higher than that of the commercial reference membrane, showing an interesting potential to be used for ion exchange membranes.

Swelling of the sulfonated resins increased with the degree of sulfonation, and this characteristic was significantly reduced after blending with PVDF. The blend containing 70 wt. (\%) of BS-2 achieved the highest conductivity values and these results were found to correlate well with the observed blend morphology. Nevertheless, these conductivity values were much lower than that found for the pure sulfonated resin.

\section{Acknowledgements}

The authors are grateful to CNPq and CAPES (Brazil) for the financial support and to Petroquímica União S/A for supplying the polymeric resins.

\section{References}

1. Carretta, N.; Tricoli, V. \& Picchioni, F. - J. Membr. Sci., 166, p.189 (2000). http://dx.doi.org/10.1016/S0376-7388(99)00258-6

2. Mikhailenko, S. D.; Zaidi, S. M. J. \& Kaliaguine, S. - Catal. Today, 67, p.225 (2001). http://dx.doi.org/10.1016/S0920-5861(01)00290-5 
3. Elabd, Y. A. \& Napadensky, E. - Polymer, 45, p.3037 (2004). http:// dx.doi.org/10.1016/j.polymer.2004.02.061

4. Sangeetha, D. - Eur. Pol. J., 41, p.2644 (2005). http://dx.doi. org/10.1016/j.eurpolymj.2005.03.018

5. Perles, C. E. - Polímeros, 18, p.281 (2008). http://dx.doi.org/10.1590/ S0104-14282008000400005

6. Kreuer, K. D. - J. Membr. Sci., 185, p.29 (2004). http://dx.doi. org/10.1016/S0376-7388(00)00632-3

7. Savadogo, O. - J. Power Sources, 127, p.135 (2004). http://dx.doi. org/10.1016/j.jpowsour.2003.09.043

8. Guan, R.; Zou, H.; Lu, D.; Gong, C. \& Liu, Y. - Eur. Pol. J., 41, p.1554 (2005). http://dx.doi.org/10.1016/j.eurpolymj.2005.01.018

9. Kucera, F. \& Jancar, J. - Polym. Eng. Sci., 38, p.783 (1998). http:// dx.doi.org/10.1002/pen.10244

10. Makowski, H. S. \& Lundberg, R. D. U.S. - "Flexible polymeric compositions comprising a normally plastic polymer sulfonated to about 0.2 to about 10 mole\% sulfonate", Patent no 3.870 .841 (1975).

11. Lehtinen, T.; Sundholm, G.; Holmberg, S.; Sundholm, F.; Björnbom, P. \& Bursell, M. - Electrochim Acta, 43, p.1881 (1998). http://dx.doi org/10.1016/S0013-4686(97)10005-6

12. Mokrini, A.; Huneault, M. A. \& Gerard, P. - J. Membr. Sci., 283, p.74 (2006). http://dx.doi.org/10.1016/j.memsci.2006.06.032
13. Bae, B. \& Kim, D. - J. Membr. Sci., 220, p.75 (2003). http://dx.doi. org/10.1016/S0376-7388(03)00216-3

14. Nagarale, R. K.; Gohil, G. S. \& Shahi, V. K. - J. Membr. Sci., 280, p.389 (2006). http://dx.doi.org/10.1016/j.memsci.2006.01.043

15. Becker, C. M. - "Obtaining and Characterization of sulfonated proton conducting styrene copolymers for development of polymer membranes", M.Sc. Dissertation, Universidade Federal do Rio Grande do Sul, Brazil (2007).

16. Rudge, A.; Davey, J.; Raistrick, I.; Gottesfeld, S. \& Ferraris, J. P. - J. Power Sources, 47, p.89 (1994). http://dx.doi.org/10.1016/0378-7753(94)80053-7

17. Celso, F.; Mauler, R. S. \& Gomes, A. S. - Polímeros, 18, p.178 (2008). http://dx.doi.org/10.1590/S0104-14282008000200016

18. Flint, S. D. \& Slade, R. C. T. - Solid State Ion., 97, p.299 (1997). http:// dx.doi.org/10.1016/S0167-2738(97)00037-4

19. Erbil, C.; Kazancioglu, E. \& Uyanik, N. - Eur. Pol. J., 40, p.1145 (2004). http://dx.doi.org/10.1016/j.eurpolymj.2003.12.024

20. Liu, Y.-C. - Mat. Chem. Phys., 77, p.791 (2002). http://dx.doi. org/10.1016/S0254-0584(02)00168-2

21. Slade, S.; Campbell, S. A.; Ralph T. R.; Walsh F. C. - J. Electrochem. Soc., 149, p. 1556 (2002). http://dx.doi.org/10.1149/1.1517281

Enviado: 07/02/11

Reenviado: $12 / 12 / 11$

Aceito: $15 / 12 / 11$ 